\title{
Can Digital Engagement Transform the Performing Arts?
}

\author{
Vince Ford \\ New York Philharmonic \\ vinceford@gmail.com
}

\author{
Munir Mandviwalla \\ Temple University \\ mandviwa@temple.edu
}

\begin{abstract}
From changing consumer relationships to demands for new experiences, performing arts institutions are under increasing pressure to embrace digital transformation. Technology is altering how audiences engage with the arts. Strategies to sustain existing formats, customers, and revenue models are unlikely to succeed. Cultural institutions in general and performing arts such as orchestras, ballets, and operas are rapidly adopting technology - with millions of social media followers, streaming, and online ticketing. Yet, these initiatives are fragmented, hard to assess. This research asks: What are the mechanisms driving digital innovation in performing arts institutions? The research approach includes field interviews with fifty performing arts organizations in the United States. The results show that engagement is an important construct for digital transformation. The components, development, instantiation, and impact of digital engagement are elaborated in a set of propositions that summarize the role of digital transformation in the performing arts.
\end{abstract}

\section{Introduction}

Through the Industrial Revolution, Great Depression, and now the Information Revolution, professional orchestras have proven resilient and relevant to culture (Hart, 1973). Orchestras, which are organized similar to opera and ballet, are important performing arts institutions that are the focus of this research. Still technology is rapidly altering the consumer landscape, so like other industries, the performing arts are under pressure to embrace digital transformation. Performing arts institutions are important because they create jobs, attract investments, generate tax revenues, and stimulate local economies through tourism and consumer purchases. They also add to the intellectual and cultural environment and enable ongoing access to arts recognized as "part of the significant life of an organized community" [11]. Yet, from 1982 and 2008 attendance at a classical music concert declined from $13 \%$ of the population to just $9.3 \%$ [34].

The world around the arts has undergone incredible transformation, the introduction of new digital innovation (DI) in the form of services, platforms, and tools remains relentless. DI has significant implications for the performing arts since it is changing how we live, altering how audiences engage with the arts [27]. To-date there has been no attempt to develop a theoretical understanding of how digital innovation can transform performing arts. Cultural institutions such as orchestras are adopting technology - with millions of social media followers, streaming services, and online ticketing [42]. Yet, these initiatives are fragmented and hard to assess [12]. Therefore, the research question of this study is: What are the mechanisms that drive digital transformation in the performing arts?

A pilot field study explored digital transformation in the performing arts using the lens of the current literature. The results of the pilot suggest that engagement is a key theoretical lever. Two follow-on field studies totaling 50 organizations in the United States further explored transformation as well as delving deeper into engagement. The results are presented as a series of propositions summarizing the role of engagement in transforming the performing arts by building on the existing literature.

\section{Literature Review}

\subsection{Performing arts}

According to the National Endowment for the Arts (NEA), performing arts organizations contributed \$9 billion to the U.S. economy in 2015 [36], employing 90,000 workers, who earned $\$ 5.6$ billion [35]. Because they enhance quality of life, performing arts institutions such as orchestras are recognized as an important aspect of community development, enriching local amenities while attracting young professionals to an area [19].

A distinguishing feature of the performing arts is how art is produced and experienced. Whether dance, music, or opera, artists use their voices, instruments, 
bodies, or other objects to perform for a live audience so that consuming performing arts is an experience shared with others. Recordings and distribution platforms allow for more private experiences.

Professional symphony orchestras are performing arts organizations whose primary mission is public performance of orchestral works of symphonic repertoire [37] and whose members are compensated for their services [1]. Ballets and operas are similar, except for the art offered on stage. With all three performing arts, the work extends beyond paid performances to include community and education events such as workshops, family concerts, talks, that focus on deepening the experience of music, dance, opera and engaging communities who would not otherwise attend the performance. For instance, in $2014,42 \%$ of offerings by orchestras were free events, many outside of the concert hall in schools and community centers reaching 2.1 million people [46].

In the United States, orchestras, ballets, and operas exist almost exclusively as non-profit organizations; though, many orchestras and operas began as for-profit ventures organized as cooperatives [7]. As cooperatives, musicians paid fees to participate in an ensemble, had management responsibilities, and shared in financial surpluses. Performance revenue deficits grew in the 20th century such that the financial model shifted to dependence on philanthropy from individual or group donors [16].

Traditionally, the performing arts focus on creation of a program, production, marketing and distribution, and the experience of live performances. [39]. Applying Porter's value chain model (1985), Preece [39] identifies the key management activities as governance, administration (operations), fundraising, and outreach.

Fundraising is a key activity representing about $60 \%$ of revenue [46]. $40 \%$ is earned revenue such as ticket sales. This means that in the performing arts there are two very different but important stakeholders: Beneficiaries that receive products they did not purchase or that they paid less than the actual cost of production, such as concert audiences, or subsidized/free events in parks. In contrast, funders cover expenses not met by ticket sales for access to other patrons, membership privileges, visibility, and the intrinsic benefit of contributing to the arts and local community.

Overall, performing arts stakeholders include: Funders: Provide contributed revenue (e.g., donors, board members, government, foundations, and sponsors). Producers: Personnel that produce, promote, manage, and fundraise (e.g., musicians, dancers, singers, managers, volunteers, guilds, and unions). Audiences: Pay to attend an event (e.g., purchase a ticket), yet not enough to cover full costs to produce the event. Community: Attend free events, such as education program or public concert, or engage online without donating or buying tickets. Most of these activities require some form of interaction.

Baumol and Bowen [2] recognized a structural flaw in the performing arts business model: a "cost disease" in which rising costs continue to outpace revenues. It is unclear from the literature how the performing arts can survive the cost disease other than the obvious but so far difficult to achieve goals of increase revenues (sell more tickets, raise more funds), reduce expenses (reduce personnel cost), and/or increase nonperformance income (sell recordings) [16]. Given changing demographics, consumer trends, and the relatively fixed costs of specialized personnel, balancing the tension between raising revenue, reducing cost and starting new initiatives has proven elusive. The challenge is immediate: In 2013, nearly half of all orchestras ran deficits [27]. Orchestras in Miami and Honolulu have closed their doors [9]. Overall, from 2003 to 2013, attendance in all the performing arts declined by $15 \%$ [27].

The literature has so far largely ignored the role of digital innovation and transformation in the performing arts. A single project, platform, or innovation is unlikely to address the structural challenges. The current mindset is likely also hindering change. For example, Preece's [39] analysis ignores how value is created and exchanged among stakeholders. Yet, much of the revenue is generated from philanthropy tied to community and social causes. It is unclear in the performing arts literature how to manage these tensions.

\subsection{Digital Innovation}

The digital innovation (DI) literature [15, 26, 33, 47,48 ] provides the conceptual tools to investigate the above tensions. For example, Fichman et al.'s [15] three dimensions of digital innovation - product, process, business model - identify broad digital innovation areas. Clearly, digital innovation can transform the product, however digitally transforming the process and business model has typically been ignored in the performing arts literature. For example, DI in artistic programming might include adding data insights that inform the selection of music, the time of year a program is presented, or how it is promoted.

While Fichman et al.'s [15] dimensions expand the lens for where DI is possible, the dimension of product does not address how physical and virtual experiences are interrelated and specifically, how product applies to entertainment or experience such as 
a live performance. One solution is to adapt the product dimension with Keeley et al.'s [26] categories of product innovation into two components: product offerings - what is happening on stage and experiences - the offstage experience. This is a helpful distinction for performing art institutions - and possibly other service and entertainment providers - whose value proposition is derived from production, presentation, or licensing of a creative good [31].

Continuing with applying Keeley et al.'s framework, the product-offering dimension provides several levels of potential digital innovation, such as the visual presentation of performance: holographic projections, lighting, amplification, video, or augmented reality. Still, there are limits to technology innovation. For example, Beethoven's Symphony No. 9, which premiered in 1824, required four French horn players to perform the work; today it cannot be made more efficient either with fewer musicians or electronic instruments. Product-experience is concerned with where the product is consumed, how it is made available, and the types of interaction between firm and customer. Abundant opportunities exist for product-experience, including live broadcasts in online channels, interactive branding campaigns, online customer service, and backstage conversations with musicians.

A range of possibilities exists for innovation beyond the performance. Keeley et al. [26] generalize innovation into specific areas of activity including A. Configuration: Profit model (earned vs. contributed income), Network (audiences, producers, funders), and Structure (non-profit, venue issue), B. Offering: Product performance (concerts, outreach), Product system (subscriptions, seasons, complementary businesses such as restaurants). C. Experience: Service (box office, artists), Channel (web, social), Brand (in the community), and Customer Engagement (loyalty programs). In this view, the lower level elements are combined to innovate new or reconfigured configurations, offerings, and experiences. For example, an activity that includes new ticket offerings (profit model), new benefits (product system), within a firm (brand), and is promoted in a firm's social media channels (channel) would produce an innovation for the firm. The above example implies though that digital innovation is likely incremental so that digital transformation emerges from such projects. In other words, transformation in performing arts might happen over time, as a collection of capabilities and resources made available by incremental innovations.

Overall, the digital innovation literature provides the tools to go beyond just doing more of the same such as generic strategies of trying to sell more tickets or raise more money to consider all of the firm's value creation activities: artistic, experience, social, relational, and financial.

\subsection{Engagement}

Given that a performance is consumed and generates experiences, the literature on marketing and engagement is thus likely relevant. Especially since study 1 (below) showed the importance of engagement. Engagement is the emotional, behavioral, and cognitive interactions between an organization and stakeholders [25]. Emotional and cognitive aspects are observed in applause, tears, laughter, and other visible responses, or through information gathering such as reading program notes. Behavioral aspects are expressed in ticket purchase, donations, attending a performance or lecture, choosing to follow on social media, or registering for a newsletter. The degree of engagement is different as the intensity of a stakeholder's participation increases [45]. Cognitive attitudes exhibited by participation relate to the process of engagement [4].

Clearly, the behavior of participating is integral to an experiential product or service such as a concert. However, engagement is distinct from participation because it also involves meaningful connections with audiences. In other words, engagement creates bidirectional connections between stakeholder and organization that are both transactional and relational [28]. For example, encountering an unsolicited advertisement about upcoming performances might increase participation but does not indicate increased engagement. However, sharing, commenting, or liking content, generates value that organizations can use to improve their strategy.

Engagement creates opportunities for dialogue and involves developing "meaningful connections" between institutions and stakeholders [17]. Attendance at a performance co-creates emotional value between audience and performers, an "artistic exchange" [5] that adds something more to the experience of attending a concert. Before and after the moment of artistic exchange stakeholders interact with firms through multiple touchpoints or channels [44], many of them digital. Different channels will likely serve different engagement needs for different stakeholders and result in different types of interactions. These interactions suggest that engagement involves exchange of different types of value: dollars for ticket purchase, access to content on a website, or backstage access to artists by following on Instagram.

Digital engagement is how people use and participate in online activities, content, data, and 
platforms $[20,18]$, such as spending more time with a performance through online streaming, following on Facebook, or registering for email newsletters. Digital engagement also indicates "apparent interest" [18]. In other words, social media feedback can illuminate what audiences enjoy or dislike, leading to new offerings, features, and investments. Digital engagement may create lasting engagement with an organization [40]. For example, 30\% of audiences under 40 feel that engaging with an organization through social media is a sign of loyalty (Cohen, 2017).

Overall, through the lens of innovation and engagement it may be possible to identify the most valuable activities and stakeholders necessary to transform the performing arts.

\section{Methodology}

The research methodology is grounded theory analysis based on in-depth interviews with subject matter experts using a semi-structured questionnaire (available from the authors). Each of the about 60minute interviews were recorded with TapeACall Pro, transcribed with Temi's "Audio to Text" service, and edited to improve accuracy.

The research approach follows Pratt's [38] recommendations for rigorous, high quality, and compelling qualitative research. Participants' perspective is presented with direct quotes; the research seeks to provide sufficient evidence for its claims; and attempts to contribute to current theory. The interview protocol was designed to elaborate on the literature reviewed above using grounded theory.

Grounded theory uses inductive reasoning to study a phenomenon of interest [8] so this research aims to advance theory through an iterative process of constant comparison and contrasting, searching for similarities and differences [32]. Conceptual categories were developed through the elaboration of existing theories [8]. Finally, since one of the authors is a senior executive in the performing arts industry, we aim to achieve Van de Ven's [43] benefits of engaged scholarship: confront questions arising in the practitioner's experience, seek multiple perspectives, examine alternative models, and ultimately, contribute knowledge to both academic theory and practice to close the "theory-practice gap" (pg. 2).

The homogeneity of modern orchestras is striking: they tend to be the same size; financed the same way; play the same repertory; similar venues; and even dress similarly [41]. Orchestras also tend to perform the same repertoire, which requires the same battery of instruments. Further, orchestras, ballet, and operas rarely compete across geographic markets for audiences and funders. It is unlikely that the Boston Symphony will compete with Los Angeles Philharmonic except for the occasional national tour. The similarity of orchestras, operas, and ballets provides a valuable opportunity to study digital transformation using qualitative analysis across different organizations.

\subsection{Study 1}

Interviews with 5 senior practitioners representing major performing art organizations in the United States - 3 orchestras, 1 ballet, and 1 opera - with a $\$ 30$ million or more budget were conducted to explore the current status of digital transformation. The results show that: 1. Organizations tend to search other industries for ideas, platforms, capabilities, and audience interaction inspiration. 2. Central to the identity of performing arts is presenting perfectly curated and executed ideas, which is in sharp contrast to the experimental process of modern digital innovation. 3. Digital brings increased emphasis on data and analysis, which generates tension between product (curatorial-focus) and commerce (consumerfocus). 4. Organizations are bound by the seasonality of the subscription business model while associated contractual obligations slow responses to emerging digital opportunities. 5. Digital projects tend to build on what came before. For example, extant ticketing systems were described by every participant as a limiting factor in expanding digital services to other areas.

In sum, resource investment is increasingly driven by the desire to engage with audiences through digital interactions. The goal is to strengthen connections for financial and social gain. Engagement is thus a key underlying consideration in most activities, and all digital investments. Overall, the results of study 1 suggest that engagement may be a key theoretical lever in explaining the role of digital transformation in the performing arts.

\subsection{Study 2 and 3}

Studies 2 and 3 includes the engagement lens in addition to the original focus on digital transformation and innovation. Since the two studies were conducted sequentially, they are grouped together for expository convenience. In sum, the studies (including study 1) represent 50 interviews with executive, senior, and mid-level staff of 39 orchestras, 6 operas, and 5 ballets with a $\$ 1$ million or greater budget based in the United States.

Given the larger sample, we applied thematic content analysis to the transcripts using a three-step 
coding process: open, axial, selective using NVivo [8]. We first identified comments on innovation and transformation as first-order concepts resulting in ninety-three codes. These codes were refined into seventeen first-order concepts such as leadership, measurement, artistic, audiences, limitations, revenue, digital priorities, communication, and promotion. Next, we looked for common attributes and connections reducing to six second-order themes termed boundary spanning, capabilities and knowledge, focus, business model, incremental innovation, and participation. Finally, similarities and differences among the second-order themes were refined into three aggregate dimensions of digital engagement termed overall engagement, value exchange, and social. The process continued until new themes and categories no longer emerged.

The results show that performing arts are in a state of digital transformation. This change is often enabled by the process of engagement and extended through digital engagement. Digital transformation is visible through increased collaboration between functions within organizations, new capabilities and skills to manage digital platforms, an emphasis on audiences' needs and desires, and an expanding view of the organization's role in communities. Overall, the changes are placing increasing demands on leaders to understand and leverage the increased investment in technology.

Digital investment in the performing arts is driven by five goals that expand the value proposition and alter the business model: increase visibility, develop audiences, enhance patron experience, increase earned revenue, and modernize operations. Digital platforms are chosen based on ability to expand reach, strengthen the brand, enable value exchange, while remaining easy-to-use and maintain. Likewise, firms understand that content needs to provide a unique perspective genuine moments, behind-the-scenes, humor, and connection to community or artists - for digital engagement.

\section{Propositions}

Based on the study findings the following are proposed as the mechanisms that drive digital transformation in the performing arts. We illustrate the findings using representative quotes.

\section{Proposition 1: Digital transformation emerges from} digital engagement.

In forty-six of the fifty interviews, the different utterances all converged in the coding to the notion that digital strategy is considered by the participants for all practical purposes to be equivalent to digital engagement. In other words, transformation likely exists as an upper tier of visible order that sits above a lower tier of substitutive and extended processes and activities [21] consisting primarily of engagement activities. Engagement may thus play the same strategic role in performing arts as just-in-time approaches did in manufacturing. It is through engagement, enabled through the organization, among audiences, funders and artists, producers and the local community that value is generated. Digitizing that engagement can transform the performing arts enterprise.

"A truly deeply engaged organization is going to have that feeling embedded in their staff; it's going to have it embedded in their artistic size. And it's going to have it embedded in their processes; they're going to have that loyalty embedded in their patrons and everything that they do." (S20)

Since a firm's needs and sophistication with digital will likely increase over time, it will likely do so in fits and starts. So a firm will move from substitution - use of technology to replace an existing feature or process - to extension - an enhanced feature or function - to transformation - a fundamental new process or product [47]. Participants described shifting away from print to online advertising and using online chat for customer inquiries rather than the phone (substitution), to personalized communications or content to create context and deepen emotional and intellectual benefits (extension), and to interactive experiences made possible through digital means (transformation). In general, the process is to move existing functions online (substitution), expand stakeholder relationship and participation online through digital engagement (extension), and reconfigure the organization to support digital engagement (transformation).

\section{Proposition 2: Engagement in the performing arts requires three dimensions: behavioral, relational, and beneficial.}

Prior literature describes three dimensions of engagement: cognitive, behavioral, and affective [5, $22,10)$. However, our results show that engagement is instantiated and practiced in the participating organizations as three distinct but related dimensions termed behavioral, relational, and beneficial (see Table 1). Importantly, some degree of all three are required for engagement.

In extant literature, the Behavioral dimension includes effort and active participation between stakeholders and the organization [10]. Though participation is integral to experiential product such as concert, we found that mutuality is just as necessary. According to the study participants, engagement is 
taking action - reading the social media post (participation) and responding with a like, share, comment, or purchase - mutual exchange.

"It's really laying a foundation for an entry into a deeper relationship probably offline."(S24)

We found that the Relational dimension includes sustained repeated interactions over time in multiple contexts, online and offline, as well as interactions before, during, and after interaction. The sustained property broadens Hollebeek et al's [23]

\section{Table 1. Engagement Dimensions}

\section{Dimension and properties}

\section{Behavioral}

Stakeholders act or react to the art form, performance, or actions of the firm.

Requires action: It is active participation, including digital aspects such as liking, sharing, commenting to in-person or virtual event attendance.

Mutual exchange: Engagement involves a mutual exchange between stakeholder and organization.

\section{Relational}

Sustained interactions in different contexts between the stakeholders and the institution.

Sustained: Begins with an initial interaction that follows with more interaction, shifting from attracting to relating.

Interactions: Represented through conversations, endorsements, interactions with artists.

Contextual: Occurs in different contexts during and around an event, onsite and offsite, through different channels.

\section{Beneficial}

Stakeholders and individuals exchange intellectual and/or emotional value.

Intellectual: Learning, including knowledge about music, organization, or artists.

Emotional: Responses such as excitement about an activity, anticipation of an upcoming event, delight or enjoyment. conceptualization to include exchange before, during, and after interaction. The Beneficial dimension includes the intellectual and emotional properties that are inseparable from the motivational aspects of experiencing the performing arts. Though literature treats these as separate, the study participants saw these elements as tied to each other. Attending a performance is both an intellectual and emotional experience. Likewise, stakeholders always have multiple motivations for exchange.

\section{Representative quotes}

“... somebody who gets an email from us ... forwards it to their grandkids saying, 'Hey, let's go to this together.' ... comments or shares our content, who advocate for us..." (S34)

"Any type of action that a fan, a guest, a patron makes with our organization, something that's voluntary. " (S23)

"Instead of sort of a one-way message, that there's some sort of action back, right? I mean, yes. Liking a post, sharing a post is great. Commenting, I find better, but when they comment or ask a question or start a dialogue, .. really rewarding." (B6)

"from the time you think you have time to participate ... and how you get that information to how we handle your interaction ... . it also extends .. when you are on our campus. And then our follow through after your experience." (S38)

" a first step to developing a much deeper relationship that would include, um, you know, a personal relationship ...." (S24)

"four and five hundred people are coming ... just to hear them talk about whatever they want to talk about ... it's doing really good things ...creating that loop of connectivity. (S25)

“...if somebody sees a trailer that they're very excited about and they say I can't wait to see this, who wants to come with me, yeah. Before and after." (O5)

"They don't know what to wear. They don't know when to clap. But, instead of dumbing it down, people want more information, more context and more connection ...." (S30)

"Letting people in on sort of the creative process. There's a lot that goes into that...Sharing with people the breadth of work that we're doing that goes on...” (B2)

“... They're excited about it. They've told their friends about it and feel real comfortable and confident when 
Multiple motivations: Includes deepening knowledge, emotional benefits, or past relationship, selling tickets or discounts from loyalty programs. somebody asks like, Hey, what's going on at [the ballet]?" (B6)

"To deepen engagement.., we have a loyalty program that all of our subscribers are automatically enrolled in that allows you to have discounts." (S28)
Proposition 3: Engagement in the performing arts occurs through three touchpoints: art form, performance, and mission.

We found that engagement between organization and stakeholders are dynamic, iterative, and contextdependent across touchpoints of performance, art form, and mission (see Table 2). The touchpoint concept is needed to include art form and mission as well as the traditional focus on performance. Art form refers to individuals engaging with a work - actively

\section{Proposition 4: Digital engagement substantially expands opportunities for engagement.}

"It is not just getting people to your concert but every step of the way through getting them the information about how to get there, them getting there and feeling comfortable, them having a great experience and then them being followed up with afterwards." (S19)

Digital engagement extends the scope and time of

Table 2. Engagement Touchpoints

\begin{tabular}{|l|l|}
\hline Touchpoints & Representative Quotes \\
\hline $\begin{array}{l}\text { Art form - Stakeholder interacts with the art } \\
\text { form, artists, or a particular work. }\end{array}$ & $\begin{array}{l}\text { "We have a local ... company that helps us move stuff and they } \\
\text { refer to it as 'their Nutcracker' ...they come to the Nutcracker each } \\
\text { year and they refer to, you know, "our Nutcracker." (B6) }\end{array}$ \\
\hline
\end{tabular}

Performance - Stakeholder interacts with the organization through attendance and consumption of product.

"Our programming is still the gateway for a lot of people. They come in and see a concert or they come to a huge concert and there's some kind of connection that they make." (S16).

"We want people in the community to know about us...to recognize as a leader as a destination ... to want to spend their time." (S21)

Mission - Stakeholder interacts with th values and purpose of the organization such as donating to community outreach or education programs.

listening or humming along (behavioral), and listening repeatedly until they have a deeper connection (relational), and gain emotional and intellectual benefits (beneficial). Engaging with the art form is distinct from engaging with a performance. For example, individuals can engage with more than 1,000 recordings of Tchaikovsky's The Nutcracker (Tchaikovsky Research, 2019) without ever engaging with a particular ballet company. Engagement with mission describes the social, financial, and organizational elements that are intellectually and emotionally beneficial to the stakeholder (e.g., a donor wants to support the arts). The three touchpoints emerged as essential across ballet, opera, and orchestras. Ninety-three percent of respondents identified performance as the primary touchpoint of engagement. Art form and mission were identified by forty percent as essential touchpoints for engagement. engagement beyond transactions such as purchase, donation, or attendance. Forty-three percent of respondents indicated that digital engagement has increased engagement with their organization. This includes preparation for an event, recall of an experience, or developing a deeper understanding of the art form. Edmonds' [14] three properties of engagement - attract, sustain, relate - describes interactions with a specific work of art in a museum space. Brown \& Ratzkin's [6] "Arc of Engagement" widens the perspective to include the preceding decisions and subsequent reflection after consuming a performance. Still, both perspectives limit engagement around the art form. As discussed earlier, engagement involves more than one touchpoint and associated tactic (see Table 3). Our findings suggest that engagement moves in stages from initial attraction to deepening engagement across the touchpoints. Therefore, digital can substantially expand opportunities for engagement through different tactics. 


\section{Proposition 5: Digital engagement increases financial performance by increasing capital.}

We found that engagement requires mutual exchange, must be beneficial, and participants must be motivated to engage. Similarly, Brodie et al. [5] suggest that engagement is ultimately expressed in commitment, loyalty, and trust. Hollebeek et al. [24] suggest that successful appeal to a stakeholder's social identity is a significant driver to increased consumption of music. Finally, recent research suggests that digital engagement increases satisfaction and attendance across audiences [13].

All of the above elements require a continuing process that generates exchange of value, physical or psychological, internal or external. We can value the impact of these exchanges as instances of capital generation [3]. Mandviwalla and Watson [29] outline economic, social, symbolic, human, and organizational capital, which we apply to describe the exchanges between the funders, producers, audiences, community, and touchpoints (see Figure 1). Funders exchange money for social capital related to the

\begin{tabular}{|c|c|}
\hline Tactic & Representative Quotes \\
\hline Advertising & $\begin{array}{l}\text { "get a customized message to a } \\
\text { customized audience for less } \\
\text { money." (S35) }\end{array}$ \\
\hline Conversations & $\begin{array}{l}\text { "respond to that two-way } \\
\text { conversation in a more meaningful } \\
\text { way." (B4) }\end{array}$ \\
\hline $\begin{array}{l}\text { Personalized } \\
\text { content }\end{array}$ & $\begin{array}{l}\text { "segment or more personalize the } \\
\text { messages." (B6) }\end{array}$ \\
\hline $\begin{array}{l}\text { Product } \\
\text { sampling }\end{array}$ & $\begin{array}{l}\text { "Opera is very expensive in terms } \\
\text { of time and money, that adoption } \\
\text { process from awareness to trial } \\
\text { takes } 2-4 \text { years." (O3) }\end{array}$ \\
\hline Storytelling & $\begin{array}{l}\text { "allows us to tell more stories that } \\
\text { might be different ways in." (S36) }\end{array}$ \\
\hline Multi-channel & $\begin{array}{l}\text { "folks who've been coming here } \\
\text { since the seventies...like } \\
\text { postcards. Next generation ...check } \\
\text { social media or visit the website." } \\
\text { (S34) }\end{array}$ \\
\hline Data & $\begin{array}{l}\text { “...an opportunity to ask } \\
\text { questions, dig a little ...” (S21) }\end{array}$ \\
\hline
\end{tabular}

touchpoint of mission while audiences exchange symbolic capital (admiration) during a performance. Stakeholders generate social capital when they digitally engage, which is different from just appropriating value. Therefore, given that it is more practical to measure digital interactions than physical reactions inside a concert - the extent and type of digital engagement (e.g., social media, website, email, and other digital metrics) may be a good proxy of engaged stakeholders that generate capital for the firm. The study participants reported increased economic capital through increased investment in digital content and platforms. In other words, digital engagement enables different forms of capital to be converted to economic capital.

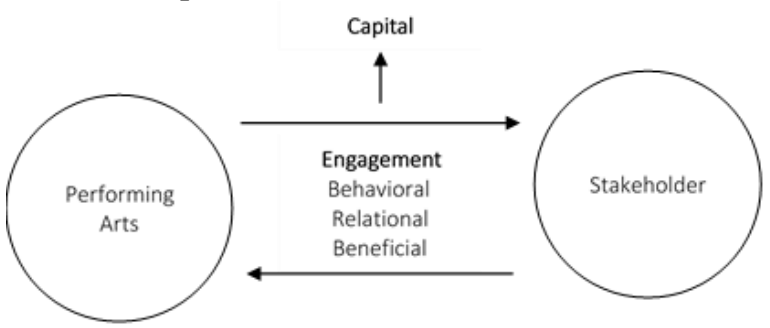

Figure 1. Engagement generates Capital

\section{Proposition 6: Investment and adoption of digital engagement leads to business model adaptation.}

As digital engagement expands opportunities, we propose that the performing arts business model will also change. Forty-seven percent of participants indicated that digital engagement was expanding the value proposition of their organization. Given that digital engagement impacts product, process, and business model [15], aspects of the business model such as value proposition, value exchange, and organization will also change. For example, platforms that drive more internal collaboration will change the organization, while projects that increase emphasis on audiences will change the underlying value proposition and value exchange process, altering the organization's view of its role in the community. All of this will lead to the digital transformation of the performing arts.

"It's like planting a seed. Engagement is an investment for the organization..."(I8)

\section{Conclusion}

This research makes several contributions to theory and practice. First, the performing arts are identified as an important area for applying digital transformation. Second, engagement was identified and defined as an important construct for digital transformation. Third, as far we are aware, this is the first study to go into the details of digital transformation and innovation in the performing arts in fifty organizations. Fourth, the dimensions 
(behavioral, relational, and beneficial), touchpoints (art form, performance, and mission), digital enablement, impact on financial performance, and business model adaption were elaborated in a set of propositions. Fifth, we expand the literature on innovation to a new unexplored area, and we build upon and expand prior conceptions of engagement.

The exploratory research has several limitations which require additional work. For example, future quantitative analysis of the three dimensions of engagement can lead to a capabilities maturity model to compare digital engagement across firms. The research was purposive focusing on performing arts in the United States limiting generalizability. Future research should include international arts organizations and other cultural institutions (e.g., museums). Due to resource constraints, we focused on engagement between audience and organization, so there is a need to more fully explore engagement among organization and funders, producers, and community, as well directly study the preferences of consumers. Finally, it will be interesting to apply the work presented here to other types of performancebased industries (e.g., rock concerts, sports, wrestling).

The cost disease threatens sustainability of the performing arts. Preferences and consumption habits are evolving, demanding digital excellence. Strategies that sustain existing business models are unlikely to meet stakeholder expectations. Digital innovation can extend the reach and relevance of the performing arts, in which digital engagement is a key theoretical mechanism for transformation. In other industries, engagement may be a 'nice to have' but in the performing arts, digitally enabled sustained engagement with subscribers, donors, and audiences may be the key predictor of overall performance. We hope that our work will allow the performing arts to more purposefully transform with more engaged stakeholders to sustain an important cultural resource.

\section{References}

[1] Allmendinger, J., \& Hackman, J. R. (1996). Organizations in Changing Environments: The Case of East German Symphony Orchestras. Administrative Science Quarterly, 41(3), 337.

[2] Baumol, W. J., \& Bowen, W. G. (1977). Performing arts-the economic dilemma: a study of problems common to theater, opera, music and dance. The MIT Press.

[3] Bourdieu, P. (1986). The forms of capital. Handbook of Theory and Research for the Sociology of Education, 241258.
[4] Bowden, J. L.-H. 2009. "The Process of Customer Engagement: A Conceptual Framework," The Journal of Marketing Theory and Practice, pp. 63-74.

[5] Brodie, R. J., Hollebeek, L. D., Jurić, B., \& Ilić, A. (2011). Customer engagement: Conceptual domain, fundamental propositions, and implications for research. Journal of Service Research, 14(3), 252-271.

[6] Brown, A. S., \& Ratzkin, R. (2011). Making Sense of Audience Engagement. The San Francisco Foundation, 1, 78.

[7] Caves, R. E. (2000). Creative industries: Contracts between art and commerce. Harvard University Press.

[8] Corbin, J. M., \& Strauss, A. (1990). Grounded theory research: Procedures, canons, and evaluative criteria. Qualitative sociology, 13(1), 3-21.

[9] Dachs, J. (2013). "New Media and New Approaches: Reinventing the Concert Hall". Fisher Dachs Associates.

[10] de Vreede, T., Andel, S., de Vreede, G. J., Spector, P., Singh, V., \& Padmanabhan, B. (2019). What is Engagement and How Do We Measure It? Toward a Domain Independent Definition and Scale. In Proceedings of the 52nd Hawaii International Conference on System Sciences.

[11] Dewey, J. (1934). Art As Experience. The Berkley Publishing Group.

[12] Dilenschneider, C. (2017, June 26). Are Mobile Apps Worth It For Cultural Organizations? (DATA).

[13] Dilenschneider, C. (2019, April 03). Game Changer: Social Media Followers Report Better Experiences At Cultural Organizations (DATA).

[14] Edmonds, E., Muller, L., \& Connell, M. (2006). On creative engagement. Visual communication, 5(3), 307-322.

[15] Fichman, R. G., Dos Santos, B. L., \& Zhiqiang (Eric) Zheng. (2014). Digital innovation as a fundamental and powerful concept in the information Systems curriculum. MIS Quarterly, 38(2), 329-343.

[16] Flanagan, R. J. (2012). The perilous life of symphony orchestras. Yale University Press.

[17] Harlow, B. (2014). The Road to Results: Effective Practices for Building Arts Audiences.

[18] Hanna, R., Rohm, A., and Crittenden, V. L. (2011). "We're All Connected: The Power of the Social Media Ecosystem," Business Horizons (54:3), "Kelley School of Business, Indiana University," pp. 265-273

[19] Hayter, C., and Pierce, S. C. (2009). Arts \& the Economy: Using Arts and Culture to Stimulate State Economic Development, p. 44. 
[20] Helsper, E. J., and Eynon, R. (2013). "Distinct Skill Pathways to Digital Engagement," European Journal of Communication (28:6), pp. 696-713

[21] Holland, J. (1995). Hidden order: How adaptation builds complexity. Basic Books.

[22] Hollebeek, L. (2011). Exploring customer brand engagement: Definition and themes. Journal of Strategic Marketing, 19(7), 555-573.

[23] Hollebeek, L. D., Glynn, M. S., \& Brodie, R. J. (2014). Consumer brand engagement in social media: Conceptualization, scale development and validation. Journal of Interactive Marketing, 28(2), 149-165.

[24] Hollebeek, L. D., Malthouse, E. C., \& Block, M. P. (2016). Sounds of music: exploring consumers' musical engagement. Journal of Consumer Marketing, 33(6), 417427.

[25] Kahn, W. A. 1990. "Psychological Conditions of Personal Engagement and Disengagement At Work," Academy of Management Journal (33:4), pp. 692-724.

[26] Keeley, L., Pikkel, R., Quinn, B., Walters, H. (2013). Ten Types of Innovation: The Discipline of Building Breakthroughs. John Wiley \& Sons, Inc.

[27] Kushner, R., \& Cohen, R. (2013). National Arts Index 2013: An Annual Measure of the Vitality of Arts and Culture in the United States: 2000-2011.

[28] Lin, N. (2001). Social capital. A theory of social structure and action. Cambridge: Cambridge University Press.

[29] Mandviwalla, M., \& Watson, R. (2014). Generating capital from social media. MIS Quarterly Executive, 13(2), 97-113.

[30] McCarthy, K. F., \& Jinnett, K. (2001). A New Framework for Building Participation in the Arts.

[31] Moyon, E., \& Lecocq, X. (2014). Rethinking business models in creative industries: the case of the French record industry. International Studies of Management \& Organization, 44(4), 83-101.

[32] Myers, M. D. (2013). Qualitative research in business and management. Sage.

[33] Nambisan, S., Lyytinen, K., Majchrzak, A., \& Song, M. (2017). Digital innovation management: Reinventing innovation management research in a digital world. MIS Quarterly, 41(1).

[34] National Endowment for the Arts. (2009). 2008 Survey of Public Participation in the Arts, Research Report 49.
[35] National Endowment for the Arts. (2017). U. S. Trends in Arts Attendance and Literary Reading : 20022017.

[36] National Endowment for the Arts. (2018). Arts Data Profile: The U.S. Arts and Cultural Production Satellite Account (1998-2015).

[37] "Orchestra Repertoire Report (ORR) 2011-2012". (2012). League of American Orchestras.

[38] Pratt, M. G. (2009). From the editors: For the lack of a boilerplate: Tips on writing up (and reviewing) qualitative research. Academy of management journal, 52(5), 856-862.

[39] Preece, S. B. (2005). The Performing Arts Value Chain. International Journal of Arts Management, 8(1), 21-32.

[40] Schultz, D. E., and Peltier, J. J. 2013. "Social Media's Slippery Slope: Challenges, Opportunities and Future Research Directions," Journal of Research in Interactive Marketing (7:2), pp. 86-99

[41] Spitzer, J., Zaslaw, N. (2005). Birth of the Orchestra 1650-1815. Oxford University Press.

[42] Uhl, Axel \& Schmid, Alexander \& Zimmermann, Robert. (2013). From the Concert Hall to the Web: How the Berliner Philharmoniker Transformed their Business Model. $360^{\circ}$ - The Business Transformation Journal. 4655.

[43] Van de Ven, A. H. (2007). Engaged scholarship: A guide for organizational and social research. Oxford University Press.

[44] Van Doorn, J., Lemon, K. N., Mittal, V., Nass, S., Pick, D., Pirner, P., and Verhoef, P. C. (2010). "Customer Engagement Behavior: Theoretical Foundations and Research Directions," Journal of Service Research (13:3), pp. 253-266.

[45] Vivek, S. D., Beatty, S. E., and Morgan, R. M. (2012). "Customer Engagement: Exploring Customer Relationships Beyond Purchase," The Journal of Marketing Theory and Practice (20:2), pp. 122-146.

[46] Voss, Z. G., Voss, G. B., Yair, K., and Lega, K. (2016). Orchestra Facts: 2006-2014 A Study of Orchestra Finances and Operations.

[47] Westerman, G., Bonnet, D., McAfee, A. (2014). Leading Digital: Turning Technology into Business Transformation. Harvard Business Review Press.

[48] Yoo, Y., Henfridsson, O., \& Lyytinen, K. (2010). Research commentary - the new organizing logic of digital innovation: an agenda for information systems research. Information Systems Research, 21(4), 724-735. 